\title{
Vaccination of pregnant cows with EspA, EspB, y-intimin, and Shiga toxin 2 proteins from Escherichia coli 0157:H7 induces high levels of specific colostral antibodies that are transferred to newborn calves
}

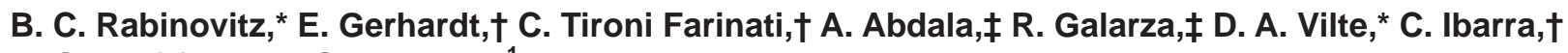 \\ A. Cataldi, $\S$ and E. C. Mercado*1 \\ *Instituto de Patobiología, Instituto Nacional de Tecnología Agropecuaria (INTA), Nicolás Repetto y De los Reseros, 1686 Hurlingham, \\ Buenos Aires, Argentina \\ †Laboratorio de Fisiopatogenia, Departamento de Fisiología, Facultad de Medicina, Universidad de Buenos Aires, Paraguay 2155 , \\ 1121 Ciudad Autónoma de Buenos Aires, Argentina \\ ‡Estación Experimental Agropecuaria Rafaela, Instituto Nacional de Tecnología Agropecuaria (INTA), Ruta 34 Km 227, 2300 Rafaela, \\ Santa Fé, Argentina \\ §Instituto de Biotecnología, Instituto Nacional de Tecnología Agropecuaria (INTA), Nicolás Repetto y De los Reseros, 1686 Hurlingham, \\ Buenos Aires, Argentina
}

\begin{abstract}
Enterohemorrhagic Escherichia coli (EHEC) O157:H7 is a major cause of intestinal disease and hemolytic uremic syndrome, a serious systemic complication that particularly affects children. Cattle are primary reservoirs for EHEC O157:H7 and the main source of infection for humans. Vaccination of cattle with different combinations of bacterial virulence factors has shown efficacy in decreasing EHEC O157:H7 shedding. It is, therefore, important to demonstrate whether vaccination of pregnant cows with EHEC O157:H7 induces high titers of transferable antibodies to avoid early colonization of calves by the bacteria. In this study we evaluated the ability of EspA, EspB, the C-terminal fragment of 280 amino acids of $\gamma$-intimin $\left(\gamma\right.$-intimin $\left.\mathrm{C}_{280}\right)$ and inactivated Shiga toxin (Stx) 2 proteins to induce specific antibodies in colostrum and their passive transference to colostrum-fed calves. Friesian pregnant cows immunized by the intramuscular route mounted significantly high serum and colostrum IgG responses against EspB and $\gamma$-intimin $\mathrm{C}_{280}$ that were efficiently transferred to their calves. Antibodies to EspB and $\gamma$-intimin $\mathrm{C}_{280}$ were detected in milk samples of vaccinated cows at $d$ 40 postparturition. Significant Stx2-neutralizing titers were also observed in colostrum from Stx2-vaccinated cows and sera from colostrum-fed calves. The results presented showed that bovine colostrum with increased levels of antibodies against EHEC O157:H7 may be obtained by systemic immunization of pregnant cows, and that these specific antibodies are efficiently transferred
\end{abstract}

Received October 26, 2011.

Accepted February 5, 2012.

${ }^{1}$ Corresponding author: emercado@cnia.inta.gov.ar to newborn calves by feeding colostrum. Hyperimmune colostrum and milk may be an alternative to protect calves from early colonization by EHEC O157:H7 and a possible key source of antibodies to block colonization and toxic activity of this bacterium

Key words: enterohemorrhagic Escherichia coli O157:H7 vaccine, immunoglobulin G, colostrum, calf

\section{INTRODUCTION}

Enterohemorrhagic Escherichia coli (EHEC) O157:H7 is a major etiologic agent of diseases in humans, whose clinical spectrum includes diarrhea, hemorrhagic colitis, and hemolytic uremic syndrome, the leading cause of chronic renal failure in children in $\mathrm{Ar}$ gentina and several other countries (Karch et al., 2005; Repetto, 2005). This bacterium produces 2 major types of Shiga toxins (Stx1 and Stx2), which are responsible for systemic damage (Scheutz and Strockbine, 2005). Current treatment is largely limited to supportive care, as no specific regimen against an E. coli O157:H7 infection exists and the use of antibiotics is not recommended. One reason for not using antibiotics is that the release of Stx from the bacterium following antibiotic treatment can worsen the clinical course (Tarr et al., 1988).

The main reservoir for EHEC O157:H7 is healthy cattle, which harbor this organism in their intestinal tract (Karmali, et al., 2010), especially in the lymphoid follicle-dense mucosa at the terminal rectum (Naylor et al., 2003). Fecal contamination of meat during slaughter, the use of raw manure as fertilizer, and the contamination of drinking water are major ways by which this organism can enter the human food chain.

In addition to Shiga toxins, EHEC O157:H7 is characterized by other virulence-associated traits, which 
enable it to colonize the intestinal mucosa of humans and animals with characteristic attaching and effacing lesions of intimately attached bacteria and effacement of the absorptive microvillar brush (Kaper et al., 2004). The attaching and effacing activity is mediated by the bacterial adhesin intimin, its translocated receptor Tir, and several effector proteins, which are translocated into the epithelial cell by a type 3 secretion system (TTSS) encoded by the locus of enterocyte effacement chromosomal pathogenicity island (McDaniel et al., 1995). Proteins EspA and EspB are 2 TTSS translocator proteins required, for the transit of effector proteins across the host cell membrane; EspA forms a filamentous structure through which effector proteins are translocated into the host cell (Kenny et al., 1997), whereas EspB is translocated into the host cell and contributes, in turn, to the creation of a pore in the eukaryotic cell membrane (Ide et al., 2001).

Many virulence factors of EHEC O157:H7 induce an immune response in the course of cattle and human infections. Oral inoculation of calves and steers with EHEC O157:H7 promotes an increase in serum antibody titers against O157 LPS and neutralizing antibodies to Stx (Johnson et al., 1996). More recently, Bretschneider et al. (2007) have demonstrated that cattle respond serologically to intimin and EspB of EHEC O157:H7 during the course of experimental infection. Antibodies against these proteins have also been detected in serum during both human EHEC ( $\mathrm{Li}$ et al., 2000) and enteropathogenic E. coli infections (Martinez et al., 1999) and in colostrum and milk from healthy women (Loureiro et al., 1998; ManjarrezHernandez et al., 2000; Parissi-Crivelli et al., 2000; Noguera-Obenza et al., 2003).

Vaccines targeting EHEC virulence determinants to prevent colonization of host cells by $E$. coli O157:H7 have been assessed with variable results in cattle (Potter et al., 2004; van Diemen et al., 2007; McNeilly et al., 2008; Smith et al., 2008; McNeilly et al., 2010; Vilte et al., 2011) and other animal models (Dean-Nystrom et al., 2002; Judge et al., 2004; Agin et al., 2005; Babiuk et al., 2008; Yekta et al., 2011). We have previously demonstrated that a vaccine containing EspB and the C-terminal fragment of 280 AA of $\gamma$-intimin $(\gamma$ - intimin $\mathrm{C}_{280}$ ) can decrease EHEC O157:H7 shedding following oral inoculation in cattle (Vilte et al., 2011). In this study, we aimed to determine whether systemic vaccination of pregnant cows with $\gamma$-intimin $\mathrm{C}_{280}$, EspA, EspB, and Stx2 could induce specific antibodies in colostrum that could be efficiently transferred to colostrum-fed calves. Passive immunization with specific antibodies may have the potential to decrease EHEC O157:H7 colonization in hosts such as cattle or humans.

\section{MATERIALS AND METHODS}

\section{Animals}

The study included 25 Friesian pregnant cows with an average age of $4 \mathrm{yr}$ and more than 2 lactations. Prior to immunization, fecal samples of all animals were confirmed to be negative for $E$. coli $\mathrm{O} 157: \mathrm{H} 7$ by immunomagnetic separation performed as described elsewhere (Vilte et al., 2011). During the period before delivery and immediately after delivery, the diet was special TMR composed of corn, soy, sorghum grains, sorghum cotton seeds, alfalfa hay, and mineral salts, with a gradual change to a similar TMR complemented with balanced food and free grazing on alfalfa after delivery and for the following $10 \mathrm{~d}$. All but one of the deliveries was natural. Calves were allowed to stay with their dams and sucking colostrum for $48 \mathrm{~h}$. Colostrum feeding of calves was monitored for a period no longer than $6 \mathrm{~h}$ after birth and proper colostration was checked by the glutaraldehyde test (Clabough et al., 1989). All of the experiments were performed at the Estación Experimental Agropecuaria Rafaela, Instituto Nacional de Tecnología Agropecuaria (Santa Fé, Argentina), with the ethical approval of the Instituto Nacional de Tecnología Agropecuaria Animal Welfare Committee.

\section{Production of Recombinant EspA, EspB, and $y$-Intimin $C_{280}$}

Histidine-tagged EspA, EspB and $\gamma$-intimin $\mathrm{C}_{280}$ genes from O157:H7 strain 146N were cloned in pRSET-A vector (Invitrogen Corp., Carlsbad, CA) and expressed in E. coli BL21 (D3)/pLysS, as described previously (Vilte et al., 2008). The amino-terminal His-tagged proteins were purified from the lysates by affinity chromatography on nickel-agarose columns (ProBond nickel-chelating resin; Invitrogen Corp.), eluted under denaturing conditions, and dialyzed in PBS at pH 7.4.

\section{Production of Stx2}

Escherichia coli DH5 $\alpha$ transformed with plasmid pGEMT-Stx2 was used to obtain the Stx2 protein (Creydt et al., 2004). Shiga toxin 2 was purified by affinity chromatography in an agarose-galabiose resin (Calbiochem Corp., La Jolla, CA) under native conditions (Goldstein et al., 2007). To determine the purity of Stx2, fractions were immunoblotted with either a monoclonal anti-verotoxin II B subunit or with a monoclonal anti-verotoxin II A subunit (both from Biodesign International Inc., Saco, ME) directed against the B 
or A subunits of Stx2. This purification procedure resulted in approximately $1 \mathrm{ng}$ of recombinant Stx $2 / \mu \mathrm{L}$, as determined by the Bradford method. For complete inactivation of Stx2, aliquots of $500 \mu \mathrm{L}$ were heated for $10 \mathrm{~min}$ at $75^{\circ} \mathrm{C}$. Inactivated Stx2 was used as immunogens.

\section{Immunization Protocol and Sample Collection}

Four separated groups of 5 pregnant cows each were i.m. immunized at 60,40 , and $20 \mathrm{~d}$ before delivery with $100 \mu \mathrm{g}$ of EspA, EspB, or $\gamma$-intimin $\mathrm{C}_{280}$, or with 100 $\mu \mathrm{g}$ of inactivated Stx2, respectively, diluted in $1 \mathrm{~mL}$ of PBS and mixed with $1 \mathrm{~mL}$ of mineral oil-based adjuvant (Montanide ISA206; Seppic, Paris, France). A control group of 5 animals received only PBS plus the adjuvant.

Serum samples were collected from cows at the time of the first immunization and at the delivery, as well as from calves at $24 \mathrm{~h}$ of birth, and stored at $-20^{\circ} \mathrm{C}$ until further processing. Colostrum samples were obtained from cows within the first $24 \mathrm{~h}$ after parturition. Milk samples were collected on d 40 of lactation. Colostrum samples were delipidated for immune assays by centrifugation $\left(1,070 \times g\right.$ at $4^{\circ} \mathrm{C}$ for $\left.45 \mathrm{~min}\right)$ and the watery phase was stored at $-20^{\circ} \mathrm{C}$.

\section{Quantification of Anti-EspA, Anti-EspB, and Anti-y-Intimin $C_{280}$ Antibodies}

Serum and colostrum samples were analyzed for the presence of IgG antibodies against EspA, EspB, and $\gamma$-intimin $\mathrm{C}_{280}$, by an ELISA as described previously (Vilte et al., 2011). Briefly, microtiter plates (Nunc Immuno MaxiSorp; Nunc A/S, Roskilde, Denmark) were coated with $100 \mu \mathrm{L}$ of either EspA, EspB, or $\gamma$-intimin $\mathrm{C}_{280}$ at $1 \mu \mathrm{g} / \mathrm{mL}$ in PBS ( $\mathrm{pH}$ 7.4) and then incubated overnight at $4^{\circ} \mathrm{C}$. After washing with PBS (pH 7.4) containing $0.05 \%$ Tween 20 (PBS-T), nonspecific binding sites were blocked with PBS-T containing 5\% skim milk for $1 \mathrm{~h}$ at $37^{\circ} \mathrm{C}$. Then, $100 \mu \mathrm{L}$ of 100 -fold diluted serum or colostrum was added to each well, and the plates were incubated for $2 \mathrm{~h}$. After washing, wells were incubated for another hour with $100 \mu \mathrm{L}$ of sheep anti-bovine IgG conjugated with horseradish peroxidase (Bethyl Laboratories, Montgomery, TX), at a dilution of 1:8,000 in PBS-T. Plates were washed 4 times. Then, 2,2'-azino-di-(3-ethyl-benzthiazoline sulfonic acid) (ABTS; Amresco Inc., Solon, OH) substrate in citrate-phosphate buffer $(\mathrm{pH} 4.2)$ plus $0.01 \% \mathrm{H}_{2} \mathrm{O}_{2}$ $(100 \mu \mathrm{L} /$ well $)$ was added. Reactions were stopped after 10 min with $100 \mu \mathrm{L}$ of $5 \%$ SDS per well and the optical density (OD) was read at $405 \mathrm{~nm}\left(\mathrm{OD}_{405}\right)$. The antibody titers of serum and colostrum were expressed in $\mathrm{OD}_{405}$. Specific IgG1 and IgG2 in colostrum were detected by an indirect ELISA using the reagents and protocol described previously (Parreño et al., 2004). In addition, pools of colostrum and milk samples of each group of animals were examined by Western blot to confirm the specificity of the antibodies measured by ELISA.

\section{Stx2 Neutralization Assay}

For the neutralization assay, Stx2 diluted in Minimum Essential Medium (MEM; Gibco; Life Technologies Corp., Carlsbad, CA) at a concentration able to inhibit cell viability by $80 \%$ was incubated with different dilutions of bovine colostrum or calf serum for $1 \mathrm{~h}$ at $37^{\circ} \mathrm{C}$ with shaking. These cocktails were then assayed in Vero cell culture by using the neutral red assay adapted from a previously described protocol (Creydt et al., 2004). Briefly, Vero cells were plated in 96-well plates and grown to confluence in complete MEM medium. Then, cells were incubated under growth-arrested conditions either with Stx2 alone or with the cocktails for $72 \mathrm{~h}$ and the neutral red uptake determined. Results are expressed as percentage of cell viability and $100 \%$ represents cells incubated under identical conditions but without the toxoid treatment.

\section{Statistical Analysis}

Serum ELISA data within each group of cows, between control- and hyperimmune colostrum-fed calves and between colostrum from the immunized and the control group of cows were compared using the Student's $t$-test. For Stx2 neutralization assays, the statistical significance between 2 mean values obtained for 2 different experimental conditions was also calculated by the Student's $t$-test. Data are shown as mean \pm standard error of the mean. In all cases, $P$-values of $<0.05 \%$ were considered significant.

\section{RESULTS}

\section{Specific IgG Activities in Serum and Colostrum of Immunized Lactating Cows}

High titers of serum IgG antibodies against $\gamma$-intimin $\mathrm{C}_{280}(P<0.01)$ and EspB $(P<0.05)$ were observed in vaccinated cows at delivery (Figures $1 \mathrm{~A}$ and $1 \mathrm{~B}$ ), but not against EspA (Figure 1C). Vaccination of dams also resulted in induction of high titers of IgG antibodies against $\operatorname{EspB}(P<0.01)$ and $\gamma$-intimin $\mathrm{C}_{280}(P<$ 0.001 ) in colostrum, compared with those in the control group (Figure 2). On the other hand, a small antibody response was induced in the colostrum from the EspA- 
vaccinated group $(P=0.05)$. Western blotting assays confirmed the specificity of the responses measured by ELISA (Figure 3A), as recombinant EspA, EspB, and $\gamma$-intimin $\mathrm{C}_{280}$ were recognized by colostrum samples. Pools of milk samples obtained from vaccinated cows on d 40 of lactation still contained antibodies reactive by Western blot with EspB and $\gamma$-intimin $\mathrm{C}_{280}$ (Figure $3 \mathrm{~B})$. The main anti- $\gamma$-intimin $\mathrm{C}_{280}$ and anti-EspB IgG isotype present in colostrum was IgG1. Titers of IgG1 and IgG2 against $\gamma$-intimin $\mathrm{C}_{280}$ were 87,040 and lower than 100, respectively, whereas titers of IgG1 and IgG2 against EspB were 8,800 and lower than 25, respectively.

\section{Specific IgG Activities in Serum from Neonatal Calves Fed with Hyperimmune Colostrum}

Calves fed colostrum from their immunized dams exhibited higher titers of serum IgG antibodies against $\gamma$-intimin $\mathrm{C}_{280}(P<0.05)$ and $\operatorname{EspB}(P<0.05)$ than calves fed colostrum from the control cows, although no significant difference existed in anti-EspA IgG titers (Figure 4).

\section{Inhibition of Stx2 Cytotoxicity in Vero Cells by Bovine Colostrum and Calf Serum}

Colostrum from Stx2-vaccinated cows and sera from the corresponding colostrum-fed calves exhibited high Stx2-neutralizing activity $(P<0.001)$ compared with their respective control groups. Colostrum inhibited the Stx2 cytotoxicity in Vero cells in a dose-dependent manner. A protective effect of colostrum was observed when Stx2 was preincubated with 1:100, 1:300, and 1:1,000 colostrum dilutions (Figure 5A). In contrast, colostrum from the control group did not have Stx2neutralizing activity. Colostrum from both the control and Stx2-vaccinated groups increased Stx2 cytotoxicity in Vero cells at 1:10 dilution. These results suggest the presence of cytotoxic substances other than anti-Stx2, which have the capacity to cause cytotoxic effects on Vero cells. Sera from calves fed with colostrum from Stx2-immunized cows also neutralized the cytotoxicity of Stx2 in Vero cells when the toxoid was preincubated with serum at 1:10 and 1:100 dilutions. These effects were not observed in sera from calves fed with colostrum from control cows (Figure 5B).

\section{DISCUSSION}

Bovine colostrum is a pre-milk substance available immediately postpartum, which contains protective antibodies that are passively acquired by the newborn calf. In humans, the transfer of maternal $\operatorname{IgG}$ to the
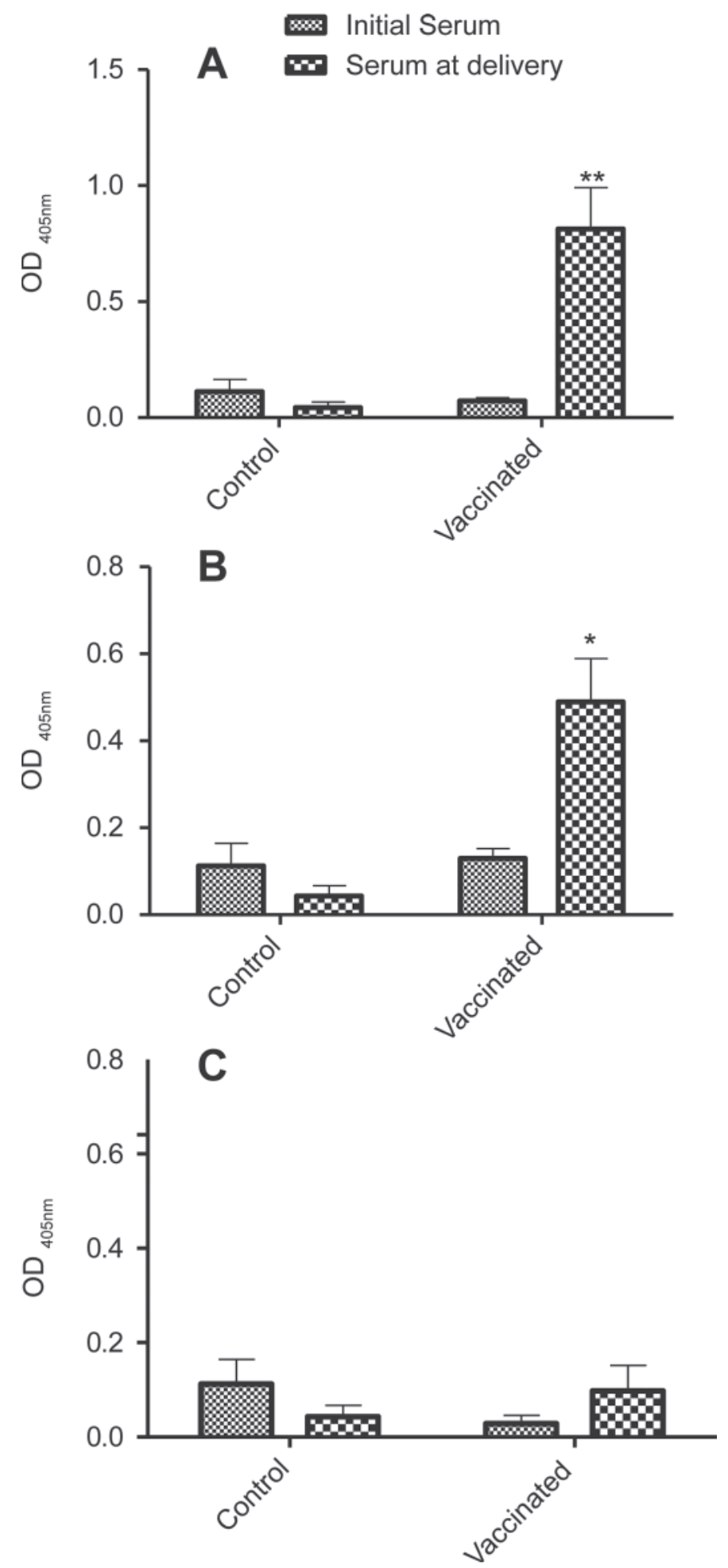

Figure 1. Immunoglobulin $\mathrm{G}$ responses in cows vaccinated with $\gamma$-intimin $\mathrm{C}_{280}(\mathrm{~A}), \operatorname{EspB}(\mathrm{B})$, and $\operatorname{EspA}(\mathrm{C})$ measured by ELISA. Data are shown as mean optical density read at $405 \mathrm{~nm}\left(\mathrm{OD}_{405}\right) \pm$ standard error of the mean. A significant increase in serum IgG against the $\gamma$-intimin $\mathrm{C}_{280}$ and EspB was observed at delivery $\left({ }^{*} P<0.05\right.$; ${ }^{* *} P$ $<0.01)$. 


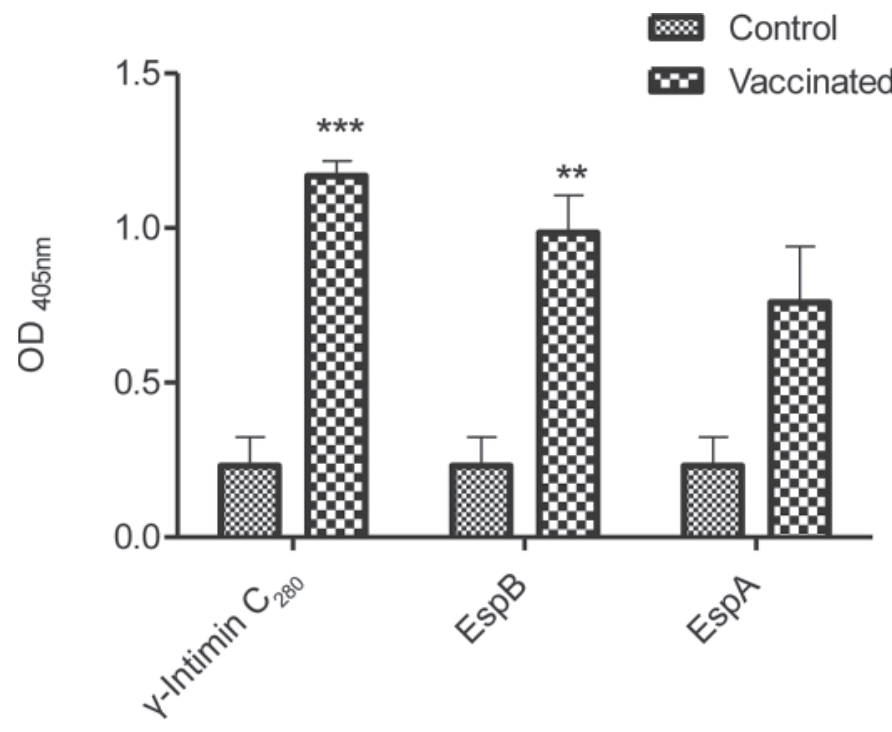

Figure 2. Levels of IgG antibodies in colostrum measured by ELISA. Data are shown as mean optical density read at $405 \mathrm{~nm}\left(\mathrm{OD}_{405}\right)$ \pm standard error of the mean. At delivery, all vaccinated cows mounted an IgG response against $\gamma$-intimin $\mathrm{C}_{280}, \mathrm{EspB}$, and EspA, compared with that of nonvaccinated cows $\left({ }^{* *} P<0.01 ;{ }^{* * *} P<0.001\right)$.

blood stream of the neonate occurs in utero across the placental membrane. In other species, including ruminants, transfer of maternal immunoglobulins to the neonate occurs exclusively via colostrum feeding. The bovine transfers large amounts of IgG, and IgG1 in particular, from the blood stream across the mammary barrier into colostrum (and milk) by a specific transport mechanism. Bovine colostrum and milk also contain much smaller amounts of locally produced $\operatorname{Ig} \mathrm{A}$ and IgM (Baintner, 2007).

Evidence that bovine colostrum is a rich source of immunoglobulin and contains neutralizing antibodies against enteric pathogens has been known for decades (Kelly, 2003). During the course of E. coli O157:H7 infection, cattle respond by producing serum and mucosal antibodies that target the pathogen (Hoffman et al., 2006; Bretschneider et al., 2007; Nart et al., 2008). In a previous work, we detected IgG antibodies against EHEC O157:H7, particularly EspA, EspB, and the highly specific $\gamma$-intimin $\mathrm{C}_{280}$ in colostrum samples from dairy cows (Vilte et al., 2008). However, the presence and level of these IgG antibodies are unpredictable and depend on the previous immune challenge. Conversely, the hyperimmune bovine colostrum (HBC) produced by immunizing cows against EHEC O157:H7 could contain much higher levels of virulence factor-specific IgG antibodies.

Passive immunization with HBC or HBC-derived immunoglobulins against several enteric pathogens, such as rotavirus, porcine epidemic diarrhea virus, Shigella dysenteriae, Cryptosporidium parvum, Helicobacter pylori, and E. coli, has been successfully applied in animals and humans by several authors since 1975 (Leiferman et al., 1975; Fayer et al., 1990; Sarker et al., 1998; Opekun et al., 1999; Ashraf et al., 2001; Shibata et al., 2001; Casswall et al., 2002). Casswall et al. (2000) obtained high titers of LPS-specific immunoglobulins in milk concentrates when cows were immunized with different serotypes of pathogenic E. coli but did not report specific antibody titers in cows. Tawfeek et al.



B)

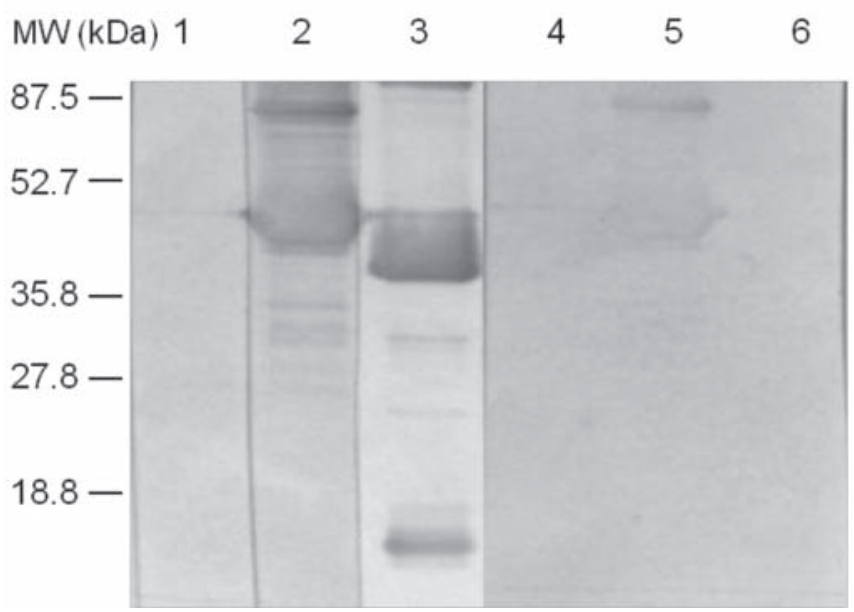

Figure 3. Western blotting of EspA, EspB, and $\gamma$-intimin $\mathrm{C}_{280}$ with pools of colostrum (A) or milk samples on d 40 of lactation (B), demonstrating the specificity of the IgG immune response. Lanes 1, 2 , and $3=$ samples of vaccinated cows reacting with EspA, EspB, and $\gamma$-intimin $\mathrm{C}_{280}$, respectively; lanes 4,5 , and $6=$ samples of placebo cows reacting with EspA, EspB, and $\gamma$-intimin $\mathrm{C}_{280}$, respectively. Colostrum samples were diluted 1:10. $\mathrm{MW}=$ molecular weight. 


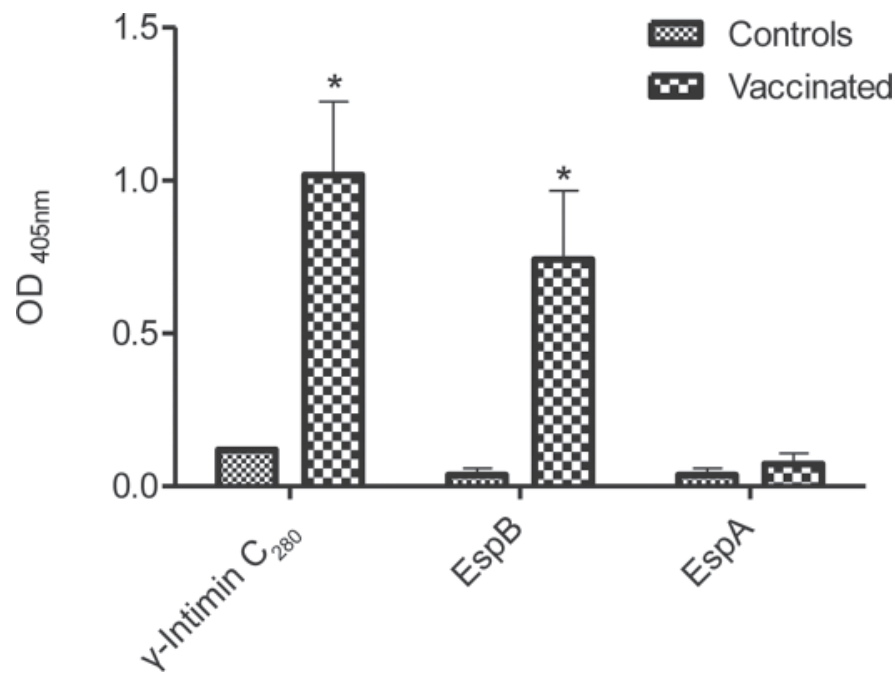

Figure 4. Levels of IgG in sera from calves measured by ELISA. Data are shown as mean optical density read at $405 \mathrm{~nm}\left(\mathrm{OD}_{405}\right) \pm$ standard error of the mean. A significant increase in serum IgG against $\gamma$-intimin $\mathrm{C}_{280}$ and EspB was observed at $24 \mathrm{~h}$ postdelivery $\left({ }^{*} P<\right.$ $0.05)$.

(2003) demonstrated that an infant formula containing anti- $E$. coli colostral antibodies from hyperimmunized cows was effective in preventing diarrhea in infants and children in a field trial. Furthermore, Kuribayashi et al. (2009) investigated the resistance of bovine colostral antibody to intestinal proteases in Beagle dogs, which were presumed to secrete proteases more abundantly than do mice and, therefore, suitable for extrapolation of results to humans. They demonstrated that bovine colostral antibody against Stx2, which contains IgG and secretory $\operatorname{IgA}$, showed resistance to proteases in the small intestine of Beagle dogs, thus suggesting the possibility of resistance to proteases in the human intestine.

It is well established that intimin and the bacterial type 3 secretion system are essential for the colonization and persistence of EHEC O157:H7 in cattle (Dean Nystrom et al., 1998; Cornick et al., 2002: Sheng et al., 2006). High serum and mucosal antibodies against some proteins belonging to the TTSS seem to protect cattle from EHEC O157:H7 colonization and to decrease the levels of bacterial shedding. In particular, intimin and EspB have been demonstrated to be highly protective antigens. These proteins were successfully assayed as immunogens in several experiments with different animal models and routes of immunization (Dean-Nystrom et al., 2002; Judge et al., 2004; Cataldi et al., 2008; McNeilly et al., 2010; Vilte et al., 2011; Yekta et al., 2011). Moreover, investigations with colostrum preparations in animal models (Funatogawa et al., 2002) and estimations of the in vitro activity of rat serum IgG or chicken egg IgY antibodies that target EHEC O157:H7 colonization antigens (Cook et al., 2007) have provided preclinical data supporting the use of anti-adherence antibodies to decrease EHEC O157:H7 colonization in hosts such as cattle or humans.

In this study, high titers of specific IgG antibodies against EspB and intimin were induced in serum and colostrum by systemic immunization of pregnant cows with 3 doses of the corresponding recombinant antigens. These antibodies were efficiently transferred to the colostrum-fed calves. Serum and colostrum anti-EspA IgG titers induced by EspA were lower than those induced by intimin or EspB. These results are in accordance with our previous observations with colostrum from healthy cows, which recognized intimin and EspB, but not EspA (Vilte et al., 2008), suggesting that EspA is the least immunogenic of the 3 proteins. The intimin and EspB antibodies present in colostrum corresponded to the IgG1 isotype, which was consistent with a high IgG1 antibody response elicited by the vaccine that entered colostrum from the blood serum.

Cows immunized with inactivated recombinant Stx2 exhibited high titers of Stx2-neutralizing antibodies in colostrum, which were efficiently transferred to the colostrum-fed newborn calves. In a previous study, 14 doses of Stx2 at 7-d intervals were used to produce high titers of bovine neutralizing colostral antibodies (Kuribayashi et al., 2006), whereas in the present study, 3 doses of vaccine were sufficient to produce colostrum showing high Stx2-neutralizing activity.

The protective effect of passive immunization with bovine colostrum on EHEC O157:H7 infection has been demonstrated in the mouse model. Funatogawa et al. (2002) observed that administration of a commercial immunoglobulin-enriched bovine colostrum to mice infected with EHEC O157:H7 inhibited attachment to the intestinal mucous membrane. Moreover, it has been demonstrated that bovine colostral antibodies against Stx1 or Stx2 increases survival rates in mice after administration of Stx1 or Stx2, or inoculation with E. coli O157:H7 producing Stx1 or Stx2 (Kuribayashi et al., 2006). Considering that Stx significantly enhance the capacity of EHEC O157:H7 to adhere to epithelial cells and to colonize the intestines of mice (Robinson et al., 2006), colostrum antibodies against Stx2 could decrease this toxin-mediated increase in bacterial adherence.

\section{CONCLUSIONS}

Bovine colostrum with increased levels of antibodies against EHEC O157:H7 was obtained by systemic immunization of cows, and specific antibodies were efficiently transferred to newborn calves by feeding colostrum. Hyperimmune colostrum and milk may be 

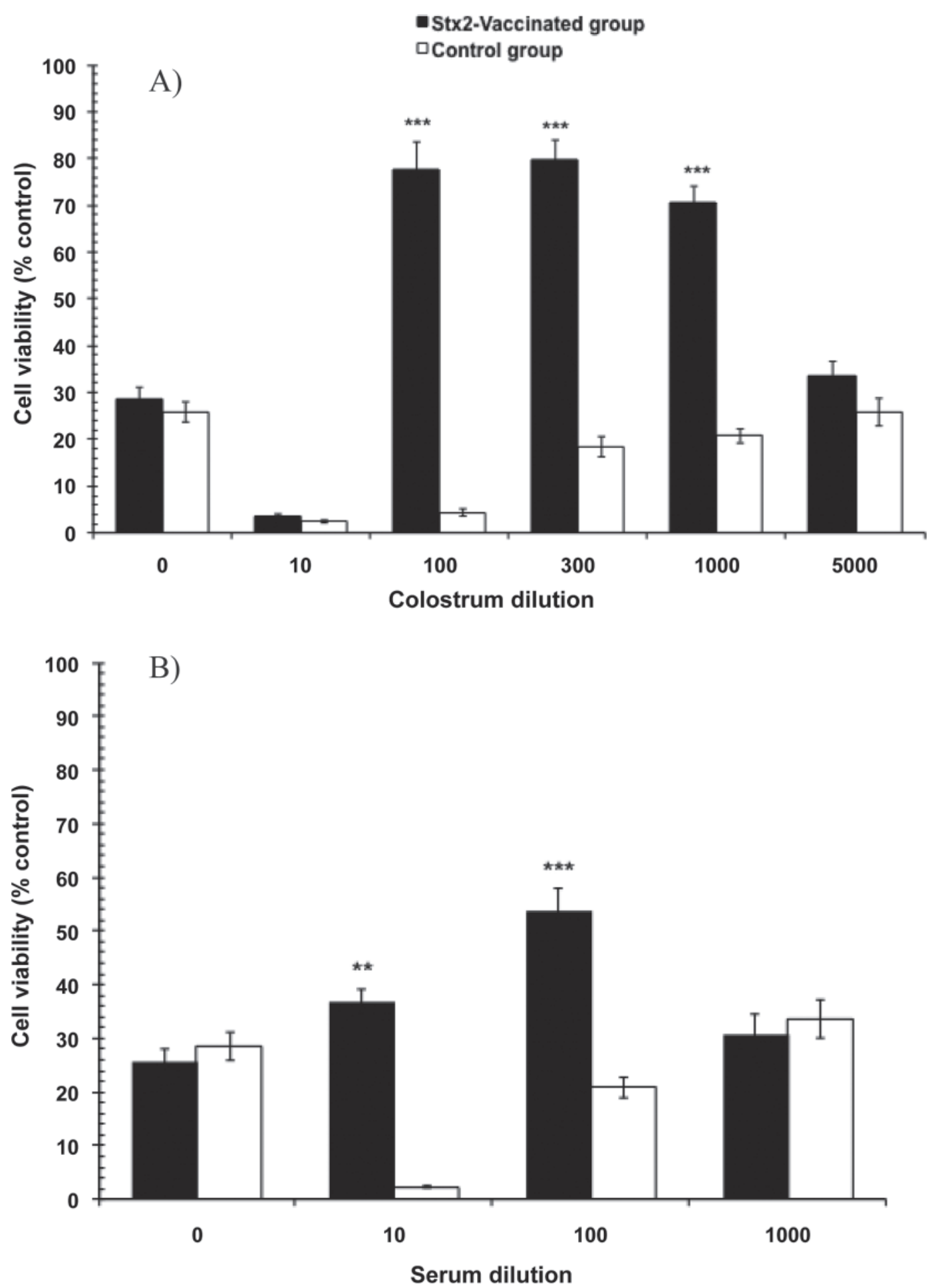

Figure 5. Shiga toxin (Stx)2 neutralization assays in Vero cells by bovine colostrum (A) and calf serum (B). Shiga toxin 2 at a concentration able to inhibit Vero cell viability by $80 \%$ was incubated with different dilutions of bovine colostrum or calf serum for $1 \mathrm{~h}$ at $37^{\circ} \mathrm{C}$. Results are expressed as percentage of cell viability, and $100 \%$ represents cells incubated under identical conditions but without the toxin treatment. Data are shown as mean \pm standard error of the mean of 3 experiments performed in sextuplicate $\left(* * P<0.01 ;{ }^{* * *} P<0.001\right)$. 
an alternative to protect calves from early colonization by EHEC O157:H7, which could result in lower contamination of the environment, and an attractive resource of specific antibodies. Further work is necessary to address if these antibodies could be useful to block colonization and toxic activity of Stx2-producing EHEC O157:H7 in the human intestine.

\section{REFERENCES}

Agin, T. S., C. Zhu, L. A. Johnson, T. E. Thate, Z. Yang, and E. C. Boedeker. 2005. Protection against hemorrhagic colitis in an animal model by oral immunization with isogenic rabbit enteropathogenic Escherichia coli attenuated by truncating intimin. Infect. Immun. 73:6608-6619.

Ashraf, H., D. Mahalanabis, A. K. Mitra, S. Tzipori, and G. J. Fuchs. 2001. Hyperimmune bovine colostrum in the treatment of shigellosis in children: A double-blind, randomized, controlled trial. Acta Paediatr. 90:1373-1378.

Babiuk, S., D. J. Asper, D. Rogan, G. K. Mutwiri, and A. A. Potter. 2008. Subcutaneous and intranasal immunization with type III secreted proteins can prevent colonization and shedding of Escherichia coli $\mathrm{O} 157: \mathrm{H} 7$ in mice. Microb. Pathog. 45:7-11.

Baintner, K. 2007. Transmission of antibodies from mother to young: Evolutionary strategies in a proteolytic environment. Vet. Immunol. Immunopathol. 117:153-161.

Bretschneider, G., E. M. Berberov, and R. A. Moxley. 2007. Isotypespecific antibody responses against Escherichia coli O157:H7 locus of enterocyte effacement proteins in adult beef cattle following experimental infection. Vet. Immunol. Immunopathol. 118:229-238.

Casswall, T. H., H. O. Nilsson, L. Björck, S. Sjöstedt, L. Xu, C. K. Nord, T. Borén, T. Wadström, and L. Hammarström. 2002. Bovine anti-Helicobacter pylori antibodies for oral immunotherapy. Scand. J. Gastroenterol. 37:1380-1385.

Casswall, T. H., S. A. Sarker, S. M. Faruque, A. Weintraub, M. J. Albert, G. J. Fuchs, N. H. Alam, A. K. Dahlström, H. Link, H. Brüssow, and L. Hammarström. 2000. Treatment of enterotoxigenic and enteropathogenic Escherichia coli-induced diarrhoea in children with bovine immunoglobulin milk concentrate from hyperimmunized cows: A double-blind, placebo-controlled, clinical trial. Scand. J. Gastroenterol. 35:711-718.

Cataldi, A., T. Yevsa, D. A. Vilte, K. Schulze, M. Castro-Parodi, M. Larzábal, C. Ibarra, E. C. Mercado, and C. A. Guzmán. 2008. Efficient immune responses against Intimin and EspB of enterohaemorragic Escherichia coli after intranasal vaccination using the TLR2/6 agonist MALP-2 as adjuvant. Vaccine 26:5662-5667.

Clabough, D. L., H. S. Conboy, and M. C. Roberts. 1989. Comparison of four screening techniques for the diagnosis of equine neonatal hypogammaglobulinemia. J. Am. Vet. Med. Assoc. 194:17171720.

Cook, S. R., P. K. Maiti, R. DeVinney, E. Allen-Vercoe, S. J. Bach, and T. A. McAllister. 2007. Avian- and mammalian-derived antibodies against adherence-associated proteins inhibit host cell colonization by Escherichia coli O157:H7. J. Appl. Microbiol. 103:1206-1219.

Cornick, N. A., S. L. Booher, and H. W. Moon. 2002. Intimin facilitates colonization by Escherichia coli O157:H7 in adult ruminants. Infect. Immun. 70:2704-2707.

Creydt, V. P., M. F. Miyakawa, F. Martín, E. Zotta, C. Silberstein, and C. Ibarra. 2004. The Shiga toxin 2 B subunit inhibits net fluid absorption in human colon and elicits fluid accumulation in rat colon loops. Braz. J. Med. Biol. Res. 37:799-808.

Dean-Nystrom, E. A., B. T. Bosworth, H. W. Moon, and A. D. O'Brien. 1998. Escherichia coli O157:H7 requires intimin for enteropathogenicity in calves. Infect. Immun. 66:4560-4563.

Dean-Nystrom, E. A., L. J. Gansheroff, M. Mills, H. W. Moon, and A. D. O'Brien. 2002. Vaccination of pregnant dams with Intimin ${ }_{\mathrm{O} 157}$ protects suckling piglets from Escherichia coli O157:H7 infection. Infect. Immun. 70:2414-2418.
Fayer, R., A. Guidry, and B. L. Blagburn. 1990. Immunotherapeutic efficacy of bovine colostral immunoglobulins from a hyperimmunized cow against cryptosporidiosis in neonatal mice. Infect. Immun. 58:2962-2965.

Funatogawa, K., T. Ide, F. Kirikae, K. Saruta, M. Nakano, and T. Kirikae. 2002. Use of immunoglobulin enriched bovine colostrum against oral challenge with enterohaemorrhagic Escherichia coli O157:H7 in mice. Microbiol. Immunol. 46:761-766.

Goldstein, J., C. F. Loidl, V. P. Creydt, J. Boccoli, and C. Ibarra. 2007. Intracerebroventricular administration of Shiga toxin type 2 induces striatal neuronal death and glial alterations: An ultrastructural study. Brain Res. 1161:106-115.

Hoffman, M. A., C. Menge, T. A. Casey, W. Laegreid, B. T. Bosworth, and E. A. Dean-Nystrom. 2006. Bovine immune response to Shiga-toxigenic Escherichia coli O157:H7. Clin. Vaccine Immunol. 13:1322-1327.

Ide, T., S. Laarmann, L. Greune, H. Schillers, H. Oberleithner, and M. A. Schmidt. 2001. Characterization of translocation pores inserted into plasma membranes by type III-secreted Esp proteins of enteropathogenic Escherichia coli. Cell. Microbiol. 3:669-679.

Johnson, R. P., W. C. Cray Jr., and S. T. Johnson. 1996. Serum antibody responses of cattle following experimental infection with Escherichia coli O157:H7. Infect. Immun. 64:1879-1883.

Judge, N. A., H. S. Mason, and A. D. O'Brien. 2004. Plant cell-based intimin vaccine given orally to mice primed with intimin reduces time of Escherichia coli O157:H7 shedding in feces. Infect. Immun. $72: 168-175$.

Kaper, J. B., J. P. Nataro, and H. L. Mobley. 2004. Pathogenic Escherichia coli. Nat. Rev. Microbiol. 2:123-140.

Karch, H., P. I. Tarr, and M. Bielaszewska. 2005. Enterohaemorrhagic Escherichia coli in human medicine. Int. J. Med. Microbiol. 295:405-418.

Karmali, M. A., V. Gannon, and J. M. Sargeant. 2010. Verocytotoxinproducing Escherichia coli (VTEC). Vet. Microbiol. 140:360-370.

Kelly, G. S. 2003. Bovine colostrums: A review of clinical uses. Altern. Med. Rev. 8:378-394. (Erratum in Altern. Med. Rev. 9:69).

Kenny, B., R. DeVinney, M. Stein, D. J. Reinscheid, E. A. Frey, and B. B. Finlay. 1997. Enteropathogenic Escherichia coli (EPEC) transfers its receptor for intimate adherence into mammalian cells. Cell 91:511-520.

Kuribayashi, T., T. Seita, M. Fukuyama, K. Furuhata, M. Honda, M. Matsumoto, H. Seguchi, and S. Yamamoto. 2006. Neutralizing activity of bovine colostral antibody against verotoxin derived from enterohemorrhagic Escherichia coli O157:H7 in mice. J. Infect. Chemother. 12:251-256.

Kuribayashi, T., T. Seita, M. Matsumoto, K. Furuhata, K. Tagata, and S. Yamamoto. 2009. Bovine colostral antibody against verotoxin 2 derived from Escherichia coli O157:H7: Resistance to proteases and effects in Beagle dogs. Comp. Med. 59:163-167.

Leiferman, K. M., J. W. Yunginger, J. B. Larson, and G. J. Gleich. 1975. The effect of immune milk as a treatment for ragweed pollinosis. Ann. Allergy 35:367-371.

Li, Y., E. Frey, A. M. R. Mackenzie, and B. B. Finlay. 2000. Human response to Escherichia coli O157:H7 infection: Antibodies to secreted virulence factors. Infect. Immun. 68:5090-5095.

Loureiro, I., G. Frankel, J. Adu-Bobie, G. Dougan, L. R. Trabulsi, and M. M. Carneiro-Sampaio. 1998. Human colostrum contains IgA antibodies reactive to enteropathogenic Escherichia coli virulenceassociated proteins: Intimin, BfpA, EspA, and EspB. J. Pediatr. Gastroenterol. Nutr. 27:166-171.

Manjarrez-Hernandez, H. A., S. Gavilanes-Parra, E. Chavez-Berrocal, A. Navarro-Ocaña, and A. Cravioto. 2000. Antigen detection in enteropathogenic Escherichia coli using secretory immunoglobulin A antibodies isolated from human breast milk. Infect. Immun. 68:5030-5036.

Martinez, M. B., C. R. Taddei, A. Ruiz-Tagle, L. R. Trabulsi, and J. A. Girón. 1999. Antibody response of children with enteropathogenic Escherichia coli infection to the bundle-forming pilus and locus of enterocyte effacement-encoded virulence determinants. J. Infect. Dis. 179:269-274. 
McDaniel, T. K., K. G. Jarvis, M. S. Donnenberg, and J. B. Kaper. 1995. A genetic locus of enterocyte effacement conserved among diverse enterobacterial pathogens. Proc. Natl. Acad. Sci. USA 92:1664-1668.

McNeilly, T. N., M. C. Mitchell, T. Rosser, S. McAteer, J. C. Low, D. G. Smith, J. F. Huntley, A. Mahajan, and D. L. Gally. 2010. Immunization of cattle with a combination of purified intimin-531, EspA and Tir significantly reduces shedding of Escherichia coli O157:H7 following oral challenge. Vaccine 28:1422-1428.

McNeilly, T. N., S. W. Naylor, A. Mahajan, M. C. Mitchell, S. McAteer, D. Deane, D. G. Smith, J. C. Low, D. L. Gally, and J. F. Huntley. 2008. Escherichia coli O157:H7 colonization in cattle following systemic and mucosal immunization with purified $\mathrm{H} 7$ flagellin. Infect. Immun. 76:2594-2602.

Nart, P., S. W. Naylor, J. F. Huntley, I. J. McKendrick, D. L. Gally, and J. C. Low. 2008. Responses of cattle to gastrointestinal colonization by Escherichia coli O157:H7. Infect. Immun. 76:5366-5372.

Naylor, S. W., J. C. Low, T. E. Besser, A. Mahajan, G. J. Gunn, M. C. Pearce, I. J. McKendrick, D. G. E. Smith, and D. L. Gally. 2003. Lymphoid follicle-dense mucosa at the terminal rectum is the principal site of colonization of enterohemorrhagic Escherichia coli O157:H7 in the bovine host. Infect. Immun. 71:1505-1512.

Noguera-Obenza, M., T. J. Ochoa, H. F. Gomez, M. L. Guerrero, I. Herrera-Insua, A. L. Morrow, G. Ruiz-Palacios, L. K. Pickering, C. A. Guzman, and T. G. Cleary. 2003. Human milk secretory antibodies against attaching and effacing Escherichia coli antigens. Emerg. Infect. Dis. 9:545-551.

Opekun, A. R., H. M. El-Zaimaity, M. S. Osato, M. A. Gilger, H. M. Malaty, M. Terry, D. R. Headon, and D. Y. Graham. 1999. Novel therapies for Helicobacter pylori infection. Aliment. Pharmacol. Ther. 13:35-42.

Parissi-Crivelli, A., J. M. Parissi-Crivelli, and J. A. Girón. 2000. Recognition of enteropathogenic Escherichia coli virulence determinants by human colostrum and serum antibodies. J. Clin. Microbiol. 38:2696-2700.

Parreño, V., C. Béjar, A. Vagnozzi, M. Barrandeguy, V. Costantini, M. I. Craig, L. Yuan, D. Hodgins, L. Saif, and F. Fernández. 2004. Modulation by colostrum-acquired maternal antibodies of systemic and mucosal antibody responses to rotavirus in calves experimentally challenged with bovine rotavirus. Vet. Immunol. Immunopathol. 100:7-24.

Potter, A. A., S. Klashinsky, Y. Li, E. Frey, H. Townsend, D. Rogan, G. Erickson, S. Hinkley, T. Klopfenstein, R. A. Moxley, D. R. Smith, and B. B. Finlay. 2004. Decreased shedding of Escherichia coli O157:H7 by cattle following vaccination with type III secreted proteins. Vaccine 22:362-369.

Repetto, H. A. 2005. Long-term course and mechanisms of progression of renal disease in hemolytic uremic syndrome. Kidney Int. Suppl. 97:S102-S106.

Robinson, C. M., J. F. Sinclair, M. J. Smith, and A. D. O'Brien. 2006. Shiga toxin of enterohemorrhagic Escherichia coli type O157:H7 promotes intestinal colonization. Proc. Natl. Acad. Sci. USA 103:9667-9672.

Sarker, S. A., T. H. Casswall, D. Mahalanabis, N. H. Alam, M. J. Albert, H. Brüssow, G. J. Fuchs, and L. Hammerström. 1998. Successful treatment of rotavirus diarrhea in children with immunoglobulin from immunized bovine colostrum. Pediatr. Infect. Dis. J. 17:1149-1154.

Scheutz, F., and N. A. Strockbine. 2005. Escherichia. Pages 607-624 in Bergey's Manual of Systematic Bacteriology. G. M. Garrity, D. J. Brenner, N. R. Krieg, and J. T. Staley, ed. Springer, New York, NY

Sheng, H., J. Y. Lim, H. J. Knecht, J. Li, and C. J. Hovde. 2006. Role of Escherichia coli O157:H7 virulence factors in colonization at the bovine terminal rectal mucosa. Infect. Immun. 74:4685-4693.

Shibata, I., M. Ono, and M. Mori. 2001. Passive protection against porcine epidemic diarrhea (PED) virus in piglets by colostrum from immunized cows. J. Vet. Med. Sci. 63:655-658.

Smith, D. R., R. A. Moxley, R. E. Peterson, T. J. Klopfenstein, G. E Erickson, and S. L. Clowser. 2008. A two-dose regimen of a vaccine against Escherichia coli O157:H7 type III secreted proteins reduced environmental transmission of the agent in a large-scale commercial beef feedlot clinical trial. Foodborne Pathog. Dis. 5:589-598

Tarr, P. I., M. A. Neill, D. L. Christie, and D. E. Anderson. 1988. Escherichia coli O157:H7 hemorrhagic colitis. N. Engl. J. Med. 318:1697.

Tawfeek, H. I., N. H. Najim, and S. Al-Mashikhi. 2003. Efficacy of an infant formula containing anti-Escherichia coli colostral antibodies from hyperimmunized cows in preventing diarrhea in infants and children: A field trial. Int. J. Infect. Dis. 7:120-128.

van Diemen, P. M., F. Dziva, A. Abu-Median, T. S. Wallis, H. van den Bosch, G. Dougan, N. Chanter, G. Frankel, and M. P. Stevens. 2007. Subunit vaccines based on intimin and Efa-1 polypeptides induce humoral immunity in cattle but do not protect against intestinal colonisation by enterohaemorrhagic Escherichia coli O157:H7 or O26:H-. Vet. Immunol. Immunopathol. 116:47-58.

Vilte, D. A., M. Larzábal, A. A. Cataldi, and E. C. Mercado. 2008. Evidence of antibodies against the LEE-encoded proteins $\gamma$-intimin and EspB from attaching and effacing Escherichia coli strains in non-immune bovine colostrum. Clin. Vaccine Immunol. 15:12081213.

Vilte, D. A., M. Larzábal, S. Garbaccio, M. Gammella, B. C. Rabinovitz, A. M. Elizondo, R. J. C. Cantet, F. Delgado, V. Meikle, A. Cataldi, and E. C. Mercado. 2011. Reduced faecal shedding of Escherichia coli $\mathrm{O} 157: \mathrm{H} 7$ in cattle following systemic vaccination with $\gamma$-intimin $\mathrm{C}_{280}$ and EspB proteins. Vaccine 29:3962-3968.

Yekta, M. A., B. M. Goddeeris, D. Vanrompay, and E. Cox. 2011. Immunization of sheep with a combination of intimin $\gamma$, EspA and EspB decreases Escherichia coli O157:H7 shedding. Vet. Immunol. Immunopathol. 140:42-46. 